plays a major part in the perception of intraoral sensation, whereas facial sensation projects to the medullary portion of this nucleus.

As our case indicates, a small lesion at the lateral pontine tegmentum can cause a pure and crossed orocrural sensory deficit, by involvement of the rostral spinal trigeminal nucleus and the lateral side of the spinothalamic tract, where the respective sensory fibres from the mouth and the lower part of the body are immediately adjacent (figure, C).

$$
\begin{array}{r}
\text { ONOFRE COMBARROS } \\
\text { JOSE BERCIANO } \\
\text { AGUSTIN OTERINO } \\
\text { Service of Neurology, University, Hospital "Marqués } \\
\text { de Valdecilla", Santander, Spain. }
\end{array}
$$

Correspondence to: Dr O Combarros, Service of Neurology, University Hospital "Marqués de Valdecilla" 39008 Santander, Spain.

1 Shintani S, Tsuruoka S, Shiigai T. Pure sensory stroke caused by a pontine infarct. Clinical, radiological, and physiological features in four patients. Stroke 1994;25: 1512-15.

2 Bassetti C, Bogousslavsky J, Barth A, Regli F. Isolated infarcts of the pons. Neurology 1996; 46:165-75.

3 Holtzman RNN, Zablozki V, Yang WC, Leeds NE. Lateral pontine tegmental hemorrhage presenting as isolated trigeminal sensory presenting as isolated trigeminal sent
neuropathy. Neurology 1987;37:704-6.

4 Matsumoto S, Okuda B, Imai T, Karneyama $M$. A sensory level on the trunk in lower lateral brainstem lesions. Neurology 1988;38: 1515-19

5 Graham SH, Sharp FR, Dillon W. Intraoral sensation in patients with brainstem lesions: role of the rostral spinal trigeminal nuclei in pons. Neurology 1988;38:1529-33.

\section{Hereditary neuropathy with liability to pressure palsies with a partial deletion of the region often duplicated in Charcot-Marie-Tooth disease, type $1 \mathrm{~A}$}

Hereditary neuropathy with liability to pressure palsies (HNPP) is an autosomal dominant disorder characterised by recurrent peripheral nerve palsies, paraesthesiae, and less often by a prominent symmetric polyneuropathy. Nerve biopsies show thickenings of myelin called tomaculae. Chance et $a l^{1}$ found such patients to have a large chromosomal deletion located in the same region as in Charcot-Marie-Tooth disease (CMT) neuropathy, type 1A. This region contains a gene for peripheral myelin protein 22 (PMP22). The role of this gene in the pathogenesis of HNPP has been shown by the discovery of a frame shift mutation creating a null mutation and resulting in the HNPP phenotype.' In the case of deletion/ duplication, a gene dosage effect has been proposed.'

In a family affected with HNPP, we found a deletion at locus D17S122 including the PMP22 gene and sparing distal loci (D17S61 and D17S125), hence confirming the expectation that deletion of a smaller region than that previously described, but including $P M P 22$, is capable of causing HNPP, and therefore supporting the role of PMP22 in HNPP.

Patient I.1 developed leg weakness at the age of 30 . Since the age of 26 , he had noticed episodes of paraesthesiae on multiple nerve trunks, at first transient, then lasting and needing several surgical decompressions. At the age of 58 , he had bilateral pes cavus, distal weakness, severe muscle atrophy, and areflexia in the lower limbs with transient paraesthesiae and cramps; sensory examination showed hypoaesthesia in the left per-
(A) Hybridisation profiles obtained with probes positioned in the region often deleted in HNPP (loci D17S122, D17S61, and D17S125) and with a control probe localised telomerically outside this region (locus D17S124). Probe pVAW409R3a detected three alleles with sizes of $2 \cdot 8,2 \cdot 7$, and $1.9 \mathrm{~kb}$ for locus D17S122, probe $\mathrm{p} E W 401 \mathrm{HE}$ detected two alleles with sizes of 5.5 and $4.4 \mathrm{~kb}$ at locus D17S61, and probe $p V A W 412 R 3 H E c$ detected two alleles with sizes of 2.6 and $1.7+0.7 \mathrm{~kb}$ for locus D17S125. Lane 1, unaffected homozygotic control; lanes 2 and 3, patients; lane 4 unaffected heterozygotic control. Probe pVAW409R3a (D17S122) did not detect 1.9 $k b$ alleles. Both alleles of locus D17S61 and D17S125 are present in patient II.1. A correct familial relation was proved with VNTR probes. The presence of one allele in locus D17S122 was proved by densitometric comparison of the $2 \cdot 7 \mathrm{~kb}$ fragment with fragment $10.5 \mathrm{~kb}$ of the external control (D17S124). (B) Eagl Southern blot hybridised with the CMT1A-REP probe $p N E A 102$. The lanes contain the DNA of a normal subject, a $C M T 1 A$ patient with the $1.5 \mathrm{Mb}$ duplication, $a$ patient with HNPP with the 1.5 Mb deletion, and the patient with HNPP (patient II.1). Patients with HNPP with a $1.5 \mathrm{Mb}$ deletion show a $370 \mathrm{~kb}$ junction fragment. No such fragment was found in patient II.1. The 270 and $220 \mathrm{~kb}$ fragments are from normal chromosomes and $150 \mathrm{~kb}$ is a junction fragment specific for CMT $1 \mathrm{~A}$ patients with a $1.5 \mathrm{Mb}$ duplication

fibres, some having an overthin myelin sheet. Rare onion bulbs were present. Tomaculae were found in $7 \%$ of the 300 internodes studied on teased fibres.

His daughter (patient II.1), had presented since the age of 26 with paraesthesiae and episodes of weakness of one or two weeks' duration in the peroneal, ulnar, or median nerve territories. At the age of 27, she had pes cavus, severe peroneal muscle atrophy, weakness, and distal extralemniscal and partially lemniscal sensory impairment in the lower limbs. Mild sensory impairment was noticed in the left ulnar and median nerve distribution. Tendon reflexes were all absent. In the upper limbs, MNCVs were normal in 1990 , but in 1995 a bilateral entrapment of the ulnar nerve at the elbow and a left carpal tunnel syndrome were present. Semithin cross sections of the sural nerve showed a slightly reduced large myelinated fibre density, tomaculae, and lesions of remyelination. All the teased fibres presented features of tomaculae and of demyelination and remyelination. Tomaculae were found in $39 \%$ of the internodes.

Molecular genetic studies were carried out for both patients by southern blotting analysis (figure, A) and pulsed field gel electrophoresis (PFGE) (figure, B).

Probe pVAW409R3a (D17S122) disclosed only one band for both patients whereas probes pEW401HE (D17S61) and pVAW412R3HEc (D17S125) were heterozygous for the second patient. Density scanning showed the presence of a single pVAW409R3a allele in both patients, and the presence of two alleles for the other probes in the first patient. The same technique showed only one copy of the PMP22 gene in the patients (not shown).

In PFGE analysis, hybridisation of EagIdigested DNA with CMT1A-REP probes usually detects deletion and duplication junction fragments in HNPP and CMT1A patients respectively. ${ }^{3}$ No such junction fragments were found for our patients with HNPP. 
Thus in our patients, molecular genetic analysis disclosed a smaller deletion than that previously reported by Chance et al, spanning about $1.5 \mathrm{Mb}$ and including al markers mapping within the CMT1A duplication. In both our patients, the $P M P 22$ gene, the dosage effect of which is thought to be responsible for the neuropathy, was deleted as well as locus D17S122, whereas both alleles D17S61 and D17S125 were present.

In addition to the deletion described by Chance et al, ${ }^{1}$ other molecular results underlying HNPP have been reported: a $2 b p$ deletion was described by Nicholson et al, ${ }^{2}$ by sequencing exon 1 of the PMP22 gene, and resulting in a reading frame shift mutation. In these affected patients, analysis of DNA disclosed the presence of two alleles for D17S122 and PMP22 probes. Mariman et $\mathrm{al}^{4}$ reported an absence of deletion in a fam ily with HNPP established by biopsy. Moreover, these authors were able to exclude linkage of the PMP22 gene and the surrounding region with the disorder present in this family. Finally, Thomas et al described histological features of tomaculous neuropathy in two patients with clinical findings of CMT associated with a mutation of the Po gene.

We emphasise the unusual character of our patients, in which they present a clinical CMT phenotype associated with the pathological features of HNPP. Prominent motor and sensory neuropathies with or without nerve palsies and HNPP pathological features have already been mentioned, but genetic analysis has only been reported by Thomas et al. ${ }^{5}$ However, Nicholson et $a l^{2}$ did not find any difference in the phenotype of patients either with or without the typica deletion of HNPP. In the study of Mariman et $a l,{ }^{4}$ the clinical signs in the family with no "HNPP deletion" were those of HNPP. Further studies could help to find out whether atypical clinical features are associated with a certain genotype.

Both HNPP and CMT1A are thought to result from a reciprocal DNA deletion or duplication of a fragment of $1.5 \mathrm{Mb}$ on chromosome 17. A partial deletion in our patients was not unexpected as partial duplications of the concerned region have also been described in CMT and the present case could be a reciprocal recombination product of such a duplication.

Probe pNEA102 detected a $7 \cdot 8 \mathrm{~kb}$ proximal and a $6.0 \mathrm{~kb}$ distal fragment belonging to CMT1A-REP repeat sequences flanking the duplicated region in CMT1A. In unaffected persons, two copies of the $7.8 \mathrm{~kb}$ fragment and two copies of the $6.0 \mathrm{~kb}$ fragment are present, whereas patients with HNPP lack one distal CMT1A-REP sequence and thus show loss of one copy of the $6.0 \mathrm{~kb}$ fragment with a subsequent difference in band density. ${ }^{1}$ We did not find a density difference between the 7.8 and $6.0 \mathrm{~kb}$ fragments of our patients with a partial deletion. Similarly, pulse field gel electrophoresis did not show the deletion junction fragments specific for patients with HNPP with a $1.5 \mathrm{Mb}$ deletion. This finding suggests that sequences other than those detected by the pNEA102 probe are involved in the mutation process of this partial deletion.

We thank Christine Berthelin, Ann Löfgren, and Susan Gamon for technical assistance. JR Lupski is acknowledged for making probe pNEA 102 avail-

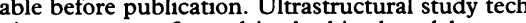
niques were performed in the histology laboratory by courtesy of Professor Izard. This work was financially supported by the Association Française contre les Myopathies (AFM). VT is a research assistant and CVB is a research associate of the
National Fund for Scientific Research (NFSR), Belgium. F CHAPON
P DIRAISON B LECHEVALIER

Service de Neurologie Dejerine, CHRU de Caen, F-14033 Caen Cedex, France G CHAZOT

Service de Neurologie, Hôpital Neurologique, F-69394 Lyon Cedex, France F VIADER

Service de Neurologie Vastel, CHRU de Caen, F-14033 Caen Cedex, France C BONNEBOUCHE A VANDENBERGHE Laboratoire de Neurogénétique, Hôpital de

l'Antiquaille, F-69321 Lyon Cedex 05, France
V TIMMERMAN
C VAN BROECKHOVEN

l'Antiquaille, F-69321 Lyon Cedex 05, France
V TIMMERMAN
C VAN BROECKHOVEN Laboratory of Neurogenetics, Born-Bunge Foundation, University of Antwerp (ULA), B-2610 Antwerpen,
Belgium Belgium
A VANDENBERGHE

Faculté de Pharmacie, Université Claude Bernard Lyon I, F-69373 Lyon Cedex 08, France

Correspondence to: $\mathrm{Dr} F$ Chapon, Service de Neurologie Dejerine, CHRU de Caen, Côte de Nacre, F-14033 Caen Cedex, France.

1 Chance PF, Abbas N, Lensch MW, et al. Two automosal dominant neuropathies result from reciprocal DNA duplication/deletion of a region on chromosome 17. Hum Mol Gene 1994;3:223-8.

2 Nicholson GA, Valentijn LJ, Cherryson AK, $e$ al. A frame shift mutation in the $P M P 22$ gene in hereditary neuropathy with liability to pressure palsies. Nat Genet 1994;6:263-6.

3 Timmerman V, Löfgren A, LeGuern E, et al. Molecular genetic analysis of the $17 \mathrm{p} 11.2$ region in patients with hereditary neuropathy with liability to pressure palsies (HNPP) Hum Genet 1996;97:26-34.

4 Mariman ECM, Gabreëls-Festen AAWM, van Beersum SEC, , heterogeneity underlying hereditary neuropathy with liability to

5 Thomas FP, Lebo RV, Rosoklija G, et al. Tomaculous neuropathy in chromosome 1 Charcot-Marie-Tooth syndrome. Acta Neuropathol 1994;87:91-7. 